\title{
Phase II study of weekly docetaxel, platinum and fluoropyramidine (DCF) in patients with advanced gastric cancer
}

\author{
Amal R. Ibrahim and Ola N. Abdel-Fattah
}

Department of Clinical Oncology and Nuclear Medicine, Faculty of Medicine, Assiut University; Assiut, Egypt.

Background and aim: The management of advanced gastric cancer (AGC) is challenging with few treatment options available. The aim of this study was to evaluate the efficacy and safety of weekly docetaxel, cisplatin and 5-fluorouracil (DCF) in patients with AGC.

Methods: Nineteen patients with confirmed AGC were enrolled in this study during the period from 2012 to 2015 . The DCF regimen consisted of docetaxel $33.3 \mathrm{mg} / \mathrm{m} 2$, cisplatin $30 \mathrm{mg} / \mathrm{m} 2$ and 5-fluorouracil $1500 \mathrm{mg} / \mathrm{m} 2$ over 24-hour continuous intravenous infusion on days 1,8 and 15 every four weeks. The treatment continued for up to 6 cycles as long as there was a response and stopped if there was disease progression or unacceptable toxicities.

Results: Complete response was achieved in only one (5.3\%) patient; partial response in twelve (63.15\%), stable disease in two $(10.6 \%)$ and progressive disease in four $(21.1 \%)$. The progression free survival varied from 3 to 25 months, with a median of 12.5 months.

Conclusion: Weekly DCF in patients with advanced gastric adenocarcinoma was associated with promising results and acceptable toxicity.

Key words: Advanced gastric cancer, Systemic chemotherapy, Docetaxel, Cisplatin, 5-fluorouracil Corresponding Author: Amal R Ibrahim

E-mail: amal3774rayan@gmail.com.

\section{INTRODUCTION}

Worldwide, gastric cancer is one of the common cancers with a declining incidence over the last decades ${ }^{1}$, 2. In Egypt, there is regional variation in the incidence of gastric cancer ${ }^{3}$. The crude incidence rates / 100.000 population in lower, middle, and upper Egypt for both sexes is 3.7, 2.9 and 4.3 respectively ${ }^{3}$.

Like many other solid tumors, the prognosis of early stage gastric cancer is relatively good. However, this early presentation is seen predominantly in Asian countries where early gastric cancer represents $10-20 \%$ of all cases. This is likely to be the result of screening programs in that region. Aiming at cure, the mainstay treatment of gastric cancer is complete resection. Chemotherapy administered peri-operatively or as an adjuvant with or without radiation therapy further improved the 5-year survival to around $40 \%{ }^{4}$.

The majority (80-90\%) of gastric cancer patients in western countries are either diagnosed in an advanced inoperable stage or develop recurrence within 5 years after curative-intent surgery ${ }^{5}$.

The prognosis of advanced gastric cancer (AGC) is dismal with a 5-year survival rate less than $10 \%$. Although there are newly introduced chemotherapeutic regimens and biologic therapies, the median overall survival (OS) of AGC patients continues to be $<1$ year $^{6}$.

Clinical trials showed that chemotherapy administered with palliative intent is superior to best supportive care in improving the survival of AGC patients and their quality of $\operatorname{life}^{5}$. However, these clinical trials recruited patients with relatively better performance status.

Although combination chemotherapy is currently accepted as a treatment for AGC, there is no agreement on the best combination. For example, the combination of docetaxel, cisplatin and 5-fluorouracil (DCF) is a preferred combination in the United States where its administration resulted in improvement of survival ${ }^{7}$.

However DCF is of benefit for patients with good performance status due to its associated toxicities. In order to enable its administration to patients with relatively lower performance status, other versions of the DCF regimen had been developed aiming at maintaining efficacy while reducing toxicities ${ }^{8}$.

The current study was conducted to determine the overall response rate to weekly DCF and its toxicity in a 
cohort of Egyptian AGC patients as well as its impact on progression free survival (PFS).

\section{PATIENTS AND METHODS}

\section{Selection of patients}

Patients were included in the study when they met the following criteria:

- Age $\geq 18$ years.

- Histologically proven unresectable, recurrent and/or metastatic gastric adenocarcinoma.

- Life expectancy $>3$ months.

- Adequate laboratory findings: $\mathrm{ANC} \geq 2 \times 10^{9} / \mathrm{L}$, platelet count $\geq 80 \times 10^{9} / \mathrm{L}$, total bilirubin $\leq$ upper normal limit (UNL), transaminases $\leq 1.5$ times $\mathrm{UNL}$, and creatinine clearance $\geq 60 \mathrm{ml} / \mathrm{min}$.

- Prior chemotherapy administration was allowed except taxanes.

- Prior radiotherapy administration was allowed.

- Written informed consent was taken from all eligible patients.

\section{Pretreatment evaluation}

Included history, physical examination and computed tomography (CT) of chest, abdomen and pelvis. Bone scan and magnetic resonance imaging (MRI) brain with contrast were done when indicated. Routine laboratory tests were done (complete blood picture, urea, creatinine, creatinine clearance, and liver function tests).

\section{Treatment}

Docetaxel $33.3 \mathrm{mg} / \mathrm{m}^{2}$, cisplatin $30 \mathrm{mg} / \mathrm{m}^{2}$ and 5-fluorouracil $1500 \mathrm{mg} / \mathrm{m}^{2}$ over 24-hour continuous intravenous infusion on days 1,8 and 15 . Cycle is repeated every 4 weeks and continued for up to 6 cycles.

Treatment was discontinued in case of disease progression or the occurrence of unacceptable toxicities.

\section{Response evaluation}

Patients were clinically evaluated every cycle, while CT body chest was done every 3 months.

Evaluation of the response was determined based on modified Response Evaluation Criteria in Solid Tumors
(RECIST) criteria version 1.1. Toxicities were evaluated according to the National Cancer Institute Common Terminology Criteria for Adverse Events (NCI CTCAE) version 3 .

\section{Statistical methods}

The primary end point of this study was the overall response rate. Secondary end points included PFS and the pattern of toxicity.

Chi Square test was used to compare differences in distribution of frequencies among various groups. $\mathrm{P}$ value of $<0.05$ was considered significant.

PFS was calculated from the time of treatment until the time of disease progression using Kaplan-Meier method ${ }^{9}$

\section{RESULTS}

From January 2013 to May 2015, 19 AGC patients were recruited at the Clinical Oncology Department of Assiut University. All patients were examined to sort out those eligible to the study, and all eligible patients were included in the study.

The characteristics of patients are shown in Table 1.

As regard the response to treatment; complete response (CR) was achieved in only one (5.3\%) patient; partial response (PR) in twelve $(63.2 \%)$, stable disease (SD) in two $(10.6 \%)$, and progressive disease (PD) in four $(21.1 \%)$.

The relation between the studied variables and response to treatment is shown in Table 2.

Eastern Cooperative Oncology Group (ECOG) performance status and the presence or absence of metastasis were associated with a significant difference in response $(p<0.02)$.

The main toxicities from weekly DCF are shown in Table 3.

There was no life threatening or grade 4 toxicities. The most frequent toxicities were vomiting and neutropenia and were mainly of grade 2 .

After a follow up for $>2$ years; the PFS ranged from 325- months, with a median of 12.5 months (Figure 1).

The mean survival was 24 months in CR patients, $14.65 \pm$ in $\mathrm{PR}, 3.5 \pm 7$ in $\mathrm{SD}$ and $3.3 \pm 57$ in $\mathrm{DP}(p<0.001)$. 


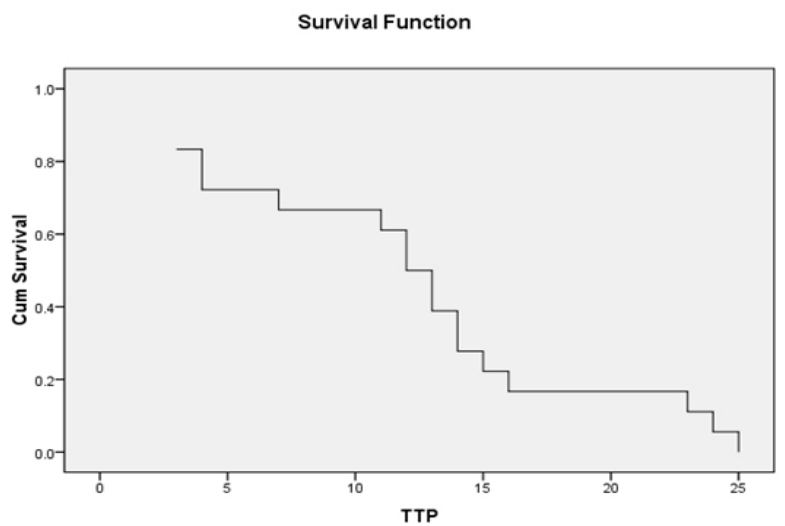

Figure 1: Kaplan Meier curve for PFS of 19 patients with advanced gastric cancer treated with weekly DCF

Table 1: Patients' characteristics

\begin{tabular}{|c|c|c|}
\hline & n. & $\%$ \\
\hline \multicolumn{3}{|l|}{ Age } \\
\hline Median (range) & \multicolumn{2}{|c|}{$60(24-73)$} \\
\hline \multicolumn{3}{|l|}{ Sex } \\
\hline Male & 11 & 57.9 \\
\hline Female & 8 & 42.1 \\
\hline \multicolumn{3}{|l|}{ Histologic subtype } \\
\hline Adenocarcinoma & 8 & 42.1 \\
\hline Signet ring carcinoma & 9 & 47.4 \\
\hline Undifferentiated carcinoma & 2 & 10.5 \\
\hline \multicolumn{3}{|l|}{ Histologic grade } \\
\hline 2 & 4 & 21.1 \\
\hline 3 & 3 & 15.8 \\
\hline 4 & 12 & 63.2 \\
\hline \multicolumn{3}{|l|}{ ECOG performance status } \\
\hline 1 & 5 & 26.3 \\
\hline 2 & 6 & 31.6 \\
\hline 3 & 6 & 31.6 \\
\hline 4 & 2 & 10.5 \\
\hline \multicolumn{3}{|l|}{ Clinical presentation } \\
\hline Abdominal pain & 10 & 52.6 \\
\hline Weight loss & 6 & 31.6 \\
\hline Gastric outlet obstruction & 5 & 26.3 \\
\hline Vomiting & 4 & 21.1 \\
\hline Gastro-esophageal reflux disease (GERD) & 1 & 5.3 \\
\hline Hematemesis & 1 & 5.3 \\
\hline Increased intracranial pressure & 1 & 5.3 \\
\hline \multicolumn{3}{|l|}{ Stage } \\
\hline Metastatic & 8 & 42.1 \\
\hline Non-metastatic & 11 & 57.9 \\
\hline \multicolumn{3}{|l|}{ Site of primary tumor } \\
\hline Upper part & 4 & 21.1 \\
\hline Middle part & 7 & 36.8 \\
\hline Lower part & 7 & 36.8 \\
\hline$>$ one part & 1 & 5.3 \\
\hline \multicolumn{3}{|l|}{ Regularity } \\
\hline Regular & 12 & 63.2 \\
\hline Irregular & 7 & 36.8 \\
\hline \multicolumn{3}{|l|}{ Previous surgery } \\
\hline No & 9 & 47.4 \\
\hline Radical surgery & 7 & 36.8 \\
\hline Palliative surgery & 3 & 15.8 \\
\hline
\end{tabular}


Table 2: The relation between variables and response

\begin{tabular}{|c|c|c|c|c|c|}
\hline \multirow{2}{*}{ Variable } & \multicolumn{4}{|c|}{ Response } & \multirow{2}{*}{ p value } \\
\hline & $\mathbf{C R}(n=1)$ & $\mathbf{P R}(n=12)$ & $\mathbf{S D}(n=2)$ & DP $(n=4)$ & \\
\hline Age & 54 & $55 \pm 13.4$ & $69.5 \pm 5$ & $48.3 \pm 16.6$ & 0.4 \\
\hline \multicolumn{6}{|l|}{ Sex } \\
\hline Male & $1(100 \%)$ & $7(58.3 \%)$ & $1(50 \%)$ & $2(50 \%)$ & 0.8 \\
\hline Female & 0 & $5(41.7 \%)$ & $1(50 \%)$ & $2(50 \%)$ & \\
\hline \multicolumn{6}{|l|}{ ECOG performance status } \\
\hline 1 & $1(100 \%)$ & $4(33.3 \%)$ & 0 & 0 & $<0.02$ \\
\hline 2 & 0 & $6(50 \%)$ & 0 & 0 & \\
\hline 3 & 0 & $2(16.7 \%)$ & $2(100 \%)$ & $2(50 \%)$ & \\
\hline 4 & 0 & 0 & 0 & $2(50 \%)$ & \\
\hline \multicolumn{6}{|l|}{ Histologic subtype } \\
\hline Adenocarcinoma & $1(100 \%)$ & $5(41.7 \%)$ & $1(50 \%)$ & $1(25 \%)$ & 0.83 \\
\hline Signet ring carcinoma & 0 & $6(50 \%)$ & $1(50 \%)$ & $2(50 \%)$ & \\
\hline Undifferentiated carcinoma & 0 & $1(8.3)$ & 0 & $1(25 \%)$ & \\
\hline \multicolumn{6}{|l|}{ Histologic grade } \\
\hline 2 & 0 & $3(25 \%)$ & $1(50 \%)$ & 0 & 0.36 \\
\hline 3 & $1(100 \%)$ & $1(8.3 \%)$ & 0 & $1(25 \%)$ & \\
\hline 4 & 0 & $8(66.7 \%)$ & $1(50 \%)$ & $3(75 \%)$ & \\
\hline \multicolumn{6}{|l|}{ Metastases } \\
\hline No & $1(100 \%)$ & $7(58.3 \%)$ & 0 & 0 & $<0.02$ \\
\hline Yes & 0 & $5(41.6 \%)$ & $2(100 \%)$ & $4(100 \%)$ & \\
\hline \multicolumn{6}{|l|}{ Regularity } \\
\hline Regular & $1(100 \%)$ & $8(66.7)$ & 0 & $1(25 \%)$ & 0.3 \\
\hline Irregular & 0 & $4(33.3)$ & $2(100 \%)$ & $3(75 \%)$ & \\
\hline
\end{tabular}

Table 3: Toxicities developed in 19 patients treated with weekly DCF

\begin{tabular}{cll}
\hline Toxicity type & $\mathbf{n .}$ & $\mathbf{\%}$ \\
\hline Abdominal pain & 1 & 5.3 \\
Anorexia & 1 & 5.3 \\
Fatigue & 2 & 10.5 \\
Nausea & 4 & 21.1 \\
Neuropathy & 9 & 47.4 \\
Neutropenia & 11 & 57.9 \\
Vomiting & 14 & 73.7 \\
\hline Toxicity grade & & \\
1 & 2 & 10.5 \\
2 & 11 & 57.9 \\
3 & 7 & 36 \\
\hline
\end{tabular}

\section{DISCUSSION}

Gastric cancer is the fifth most common cancer in the world in both sexes, after cancers of the lung, breast, colorectum, and prostate. It is the third leading cause of cancer death in both sexes worldwide ${ }^{10}$. Because the majority of patients present in an already advanced stage, gastric cancer remains difficult to cure.

The primary site in this study according to the relationship to long axis of the stomach was more common in the middle and lower parts $(36.8 \%$ for each), followed by the upper part $(21.1 \%)$ and combination of more than one part in about $(5.3 \%)$ and this finding regarding the site was comparable to other studies.

The median age of our patients was 60 years which relatively younger than that reported in other studies in which the median age at diagnosis was 69 years ${ }^{11}$. In our study; males were more commonly affected than females with male to female ratio of 1.4: 1. However, worldwide gastric cancer rates were about twice as high in men as in women ${ }^{12}$. Fifty-eight percent of included patients had metastatic disease which is comparable to that reported in the literature ${ }^{13}$. Adenocarcinoma was the only histologic type confirmed in the present study, with signet ring subtype in $47 \%$ of patients, and undifferentiated subtype in $11 \%$ of them; however; adenocarcinoma represented about $90-95 \%$ in the World Health Organization classification ${ }^{14}$. This is likely due to the small sample size.

The number of chemotherapeutic drugs used in AGC is increasing and belongs to many classes including taxanes, platinums, fluoropyramidines and others. However, there is no agreement on the best combination regimen of palliative chemotherapy and the overall response is not satisfactory with few patients achieving complete remission. In comparison to best supportive care, combining 5-FU to etoposide / anthracycline + methotrexate improved $\mathrm{OS}^{15}$. Combination chemotherapy 


Vol. 11 | No. 3-4 $2015 \quad$ Ibrahim \& Abdel-Fattah

regimens containing 5-FU, cisplatin, doxorubicin and mitomycin was found to be superior to single agent 5-FU in randomized clinical trials in terms of response rate and PFS $^{12}$.

The efficacy of docetaxel against gastric cancer has been demonstrated in many trials as a single agent with an overall response rate around $20 \%$, in addition to the synergistic effect when added to platinum compounds ${ }^{16}$, ${ }^{17}$. However, the toxicity resulting from adding docetaxel to combinations necessitated the search for administration schedules with less toxicity profile and better tolerability, such as weekly administration of docetaxel and the use of granulocyte-macrophage colony-stimulating factor ${ }^{18}$.

The DCF regimen was proven to be superior to the combination of cisplatin and 5-FU in the V325 phase III randomized controlled trial in patients with $\mathrm{AGC}^{19}$. In that trial, DCF resulted in a higher response rate, longer time to progression and better overall survival ${ }^{19}$. In addition, a positive impact on performance status and quality of life had been demonstrated ${ }^{20}$. However, the DCF regimen has been criticized for its toxicity profile; especially, neurtopenia and neutropenic fever.

In another study that included weekly docetaxel in addition to continuous infusion 5-FU and weekly cisplatin in AGC patients, the overall response rate was $26 \%{ }^{21}$.

In an attempt to reduce the toxicity resulting from the inclusion of docetaxel in combinations for patients with advanced gastric and esophageal cancer, Ho et al. administered docetaxel at a low weekly dose of $20 \mathrm{mg} / \mathrm{m}^{2}$ combined with cisplatin and 5-FU for 6 weeks and rest for 2 weeks ${ }^{22}$. This was associated with a relatively good response rate $(27 \% \mathrm{PR}$ and $45 \% \mathrm{SD})$ with lower rate of hematologic toxicity ${ }^{21}$.

The ORR in our study was $68.35 \%$ which was higher than previously reported. However, it should be taken into consideration that our study included a small sample size and the lack of comparison to a standard treatment. This better ORR was translated into better PFS (12.5 months). The main toxicities in our study were vomiting $(73.7 \%)$, neutropenia $(57.9 \%)$, neuropathy $(47.4 \%)$, and fatigue $(10.5 \%)$. grade 2 toxicity was predominant $(57.9 \%)$, grade 3 in $(36.8 \%)$, and grade 1 in $(10.5 \%)$ of patients. no grade 4 was developed.

\section{CONCLUSION}

Weekly DCF in Egyptian patients with AGC was associated with promising results and acceptable toxicity.
There is a need to be comparing the DCF regimen with standard regimens especially the every 3 weeks DCF.

\section{REFERENCES}

1. Jemal A, Bray F, Center MM, et al. Global cancer statistics. CA Cancer J Clin. 2011;61:69.

2. Zhu AL and Sonnenberg A. Is gastric cancer again rising? J Clin Gastroenterol 2012;46:804.

3. National Cancer Registry Program of Egypt, 2008. http:// www.cancerregistry.gov.eg.

4. Sakuramoto S, Sasako M, Yamaguchi T et al. ACTS-GC group. Adjuvant chemotherapy for gastric cancer with S-1, an oral fluoropyrimidine. N Engl J Med. 2007;357:1810 1820

5. Wagner AD, Unverzagt $\mathrm{S}$, Grothe $\mathrm{W}$ et al. Chemotherapy for advanced gastric cancer. Cochrane Database Syst Rev. 2010;3CD004064.

6. Power DG, Kelsen DP and Shah MA. Advanced gastric cancer - slow but steady progress. Cancer Treat Rev. 2010;36:384-392.

7. Van Cutsem E, Moiseyenko VM, Tjulandin S et al. V325 study group. Phase 3 study of docetaxel and cisplatin plus fluorouracil compared with cisplatin and fluorouracil as first-line therapy for advanced gastric cancer: a report of the V325 Study Group. J Clin Oncol. 2006;24:4991-4997.

8. Tebbutt NC, Cummins MM, Sourjina T, et al. Randomised, non-comparative Phase 2 study of weekly docetaxel with cisplatin and 5-fluorouracil or with capecitabine in oesophagogastric cancer: the AGITG ATTAX trial. Br J Cancer. 2010;102:475-481.

9. Kaplan EL and Meier P. Non-parametric estimation for incomplete observation. J Am Stat Assoc.1958;53:457 -481.

10. GLOBOCAN Cancer Facts Sheets: stomach cancer-IARC: 2012. Available at: http://globocan.iarc.fr/Default.aspx

11. Surveillance, Epidemiology and End Results Program. SEER Stat Fact Sheets: Stomach Cancer. National Cancer Institute. Available at http://seer.cancer.gov/statfacts/html/ stomach.html. Accessed May 21, 2015.

12. American Cancer Society: What are the key statistics about stomach cancer?. American Cancer Society. Available at http://www.cancer.org/cancer/stomachcancer/ detailedguide/stomach-cancer-key-statistics. Accessed May 21, 2015.

13. Avital I, Pisters PWT, Kelsen DP, et al. Cancer of the Stomach. In: DeVita VT, Lawrence TS and Rosenberg SA. DeVita, Hellman, and Rosenberg's Cancer: Principles and Practice of Oncology. $9^{\text {th }}$ ed. Philadelphia: Lippincott Williams \& Wilkins, 2011. Pp: 924-954.

14. Stomach. In: Edge SB, Byrd DR, Compton CC, et al. AJCC Cancer Staging Manual. $7^{\text {th }}$ ed. New York: Springer; 2002. Pp: 120.

15. Ooi $\mathrm{CH}$, Ivanova $\mathrm{T}, \mathrm{Wu} \mathrm{J}$, et al. Oncogenic pathway combinations predict clinical prognosis in gastric cancer. PLoS Genet. 2009;5:e1000676. 
16. Steevens J, Schouten LJ, Goldbohm RA, et al. Alcohol consumption, cigarette smoking and risk of subtypes of oesophageal and gastric cancer: a prospective cohort study. Gut. 2010;59:39-48.

17. Cardwell CR, Abnet CC, Cantwell MM, et al. Exposure to oral bisphosphonates and risk of esophageal cancer. JAMA. 2010, 11;304:657-663.

18. Khokhar NZ, Jiang Y, Benson $\mathrm{AB} 3^{\text {rd }}$, et al. Refining docetaxel-containing therapy for gastric cancer. Gastrointest Cancer Res. 2011;4:96-105.

19. Filippi L, D'Arienzo M, Scopinaro F, et al. Usefulness of dual-time point imaging after carbonated water for the fluorodeoxyglucose positron emission imaging of peritoneal carcinomatosis in colon cancer. Cancer Biother Radiopharm. 2013;28:29-33.
20. Brooks M : Adjuvant Chemo Boosts Survival in Advanced Stomach Cancer. Medscape [serial online]. Available at http://www.medscape.com/viewarticle/807504. 2013; Accessed July 15.

21. Wang B, Zhang W, Hong X, et al. Phase I dose-escalating study of 24-h continuous infusion of 5-fluorouracil in combination with weekly docetaxel and cisplatin in patients with advanced gastric cancer. Cancer Chemother Pharmacol 2009;63:213 -218.

22. Ho L, Phan AT, Jhamb J, et al. Retrospective review of docetaxel, cisplatin, and 5-FU (DCF) given on weekly basis for the treatment of advanced gastric or esophageal cancer. J Clin Oncol. 2008; 26:15525. 